\title{
Algumas considerações sobre a adoção de parcerias/convênios para oferta de vagas na educação infantil
}

\author{
Some considerations about the adoption of partnerships/ \\ agreements for the vacancies supply in early childhood \\ education
}

\section{Jaqueline dos Santos Oliveira ${ }^{1}$}

\section{Resumo:}

Tendo em vista a consolidação de parcerias/convênios entre os municípios paulistas e o setor privado para oferta educacional (ADRIÃO; GARCIA; BORGHI; ARELARO, 2009), o presente trabalho visa apresentar algumas considerações sobre as condições jurídicas e administrativas para o estabelecimento de parcerias entre a administração pública municipal e entidades privadas, tomando por objeto de análise as parcerias/convênios para oferta de vagas na educação infantil. O processo metodológico utilizado foi a revisão bibliográfica e dados de pesquisa de iniciação científica "Oferta Educacional nas creches e parcerias público-privado nos municípios paulistas de 100.000 a 500.000", financiada pela FAPESP. Observou-se diferentes modalidades de parceria entre o setor público e o privado presente em diferentes documentos legais, assim como a tendência de privatização da educação pública.

Palavras-chave: Parcerias público-privadas. Convênios. Educação infantil.

\begin{abstract}
:
Given the consolidation of partnerships / agreements between the paulistas counties and the private sector for educational provision (ADRIÃO, GARCIA, BORGHI; ARELARO, 2009), this paper presents some considerations about the legal and administrative conditions for the establishment of partnerships between the municipal public administration and private entities, taking as object of analysis the partnerships / agreements for the supply of vacancies in early childhood education. The methodological process used was the literature review and survey data from an undergraduate research called "Nursery education provision and public-private partnerships in the paulistas counties from 100,000 to 500,000", funded by FAPESP. There are different forms of partnerships between public and private sectors in many different legal documents, as well as the trend of privatization of public education.
\end{abstract}

Keywords: Public-private partnerships. Agreements. Childhood Education.

1 Pedagoga - UNESP Rio Claro. Mestranda - PPGE Instituto de Biociências - UNESP Rio Claro. E-mail: jackylyny06@yahoo.com.br 


\section{Introdução}

Na década de 1990 como "[...] resposta a uma suposta crise de eficácia da administração pública" (ADRIÃO, BORGHI, 2008, p. 99) é implantada no Brasil a reforma do Estado, sintetizada no Plano Diretor de Reforma do Aparelho do Estado (PDRAE) promulgado pelo governo federal, que propõe então a administração gerencial e a transferência da oferta de serviços públicos para as esferas administrativas locais, via mecanismos de descentralização.

Sendo a implementação de parcerias entre a esfera pública, entendida como estatal, e a privada uma das estratégias para a reforma do Estado. Servindo as parcerias ao objetivo de diminuição do tamanho do aparelho do Estado.

Nesse período, a principal estratégia adotada para a reforma da educação básica foi a transferência da responsabilidade sobre a maior parte da oferta educativa (educação infantil e ensino fundamental) para os municípios - aprofundada e generalizada pelo sistema de financiamento implantado no país, a partir de 1996: o Fundo de Manutenção e Desenvolvimento do Ensino Fundamental e de Valorização do Magistério - FUNDEF. (ADRIÃO; GARCIA; BORGHI; ARELARO, 2009).

Para Pires (2009), a reforma educacional dos anos 1990

[...] coloca a educação como um eixo entre a reforma e a produtividade. Tem por objetivo declarado, assegurá-la para todos, desde que seja relevante e eficaz, ocorrendo mudanças de ordem prática no sistema educativo, tais como: maior flexibilidade, descentralização e competitividade, acarretando em novos marcos conceituais e o Estado um mero fiscalizador das políticas educacionais (p.36).

Neste sentido Pires (2009) afirma que "A relação público - privada na educação possui o condão de guiar a educação pública para que se privilegie a formação, para o atendimento, essencialmente, das necessidades do mercado, e não visando a emancipação dos indivíduos" (p.38).

Essa articulação entre a administração pública e a esfera privada tem assumido novos contornos em função da reforma do Estado brasileiro e é uma tendência que tem se multiplicado na área educacional nos municípios paulistas a partir da municipalização do ensino fundamental, com a consolidação de parcerias, convênios envolvendo principalmente, a compra de sistemas de ensino privado pelas redes municipais de ensino, a subvenção de vagas em entidades privadas (oferta de vagas) e a contratação de instituições privadas visando à elaboração de políticas educacionais para a gestão municipal, entre outras (ADRIÃO; GARCIA; BORGHI; ARELARO, 2009; SILVEIRA, 2009).

Após esta introdução, apresentamos uma sucinta análise da adoção de parcerias entre o setor público e a esfera privada para oferta educacional, apontando alguns dos diferentes instrumentos jurídicos para formalização de parcerias e, como exemplo, trazemos as parcerias para oferta de vagas na educação infantil que foi objeto de análise em pesquisa concluída em 2010 (OLIVEIRA, 2010).

\section{Parcerias: características e o caso de alguns municípios paulistas grandes}

O termo parceria, segundo Di Pietro (2006), significa o mesmo que sociedade e traz em si a idéia de lucro, motivo pelo qual alguns resistem em utilizá-la. Para Di Pietro "[...] o vocábulo parceria é utilizado para designar todas as formas de sociedade que, sem formar uma nova pessoa jurídica, são organizadas entre os setores público e privado, para a consecução de fins de interesse público" (2006, p. 40).

É importante ressaltar conforme aponta a autora, que "[...] a natureza econômica da atividade não é essencial para caracterizar a parceria, como também não o é a idéia de lucro, já que a parceria pode dar-se com entidades sem fins lucrativos [...]" (DI PIETRO, 2006, p.40). Portanto, a parceria pode servir a variados objetivos e formalizar-se por diferentes instrumentos jurídicos. Neste trabalho, o termo parceria é entendido como os acordos formalmente firmados pelo poder público com entidades privadas (BEZERRA, 2008).

Conforme aponta Silveira (2009) a "relação de parceria da esfera pública, estatal, com o setor privado se faz por meio de contratos, parcerias e convênios" (p. 145). Segundo esta mesma autora "[...] verificar as normas legais para esse procedimento se faz fundamental para compreender as estratégias e arranjos utilizados para a introdução de mecanismos de privatização na educação" (SILVEIRA, 2009, p.145). 
No direito positivo brasileiro, vários instrumentos de parceria estão previstos: concessão e a permissão de serviços públicos, concessão de obra pública, concessão patrocinada e administrativa (que discutiremos no decorrer deste trabalho), contrato de gestão, termo de parceria, convênios, consórcios, contratos de empreitada e contratos de fornecimento de mão-de-obra. Sendo que a escolha da modalidade de parceria não é arbitrária, mas deve ser feita em função do tipo de atividade (DI PIETRO, 2006).

Egle Bezerra (2008) sistematizou as modalidades de parceria entre o setor público e o privado presente em diferentes documentos legais, entre eles o convênio.

Os convênios são regidos pela Lei federal n 8.666 , de 21 de junho de 1993. E

[...] constitui-se em uma das modalidades assumidas pela forma de fomento como um instrumento utilizado pelo Poder Público para se associar com entidades públicas ou privadas e distingue-se do contrato por ser concernente a interesses recíprocos, no qual os entes conveniados apresentam objetivos institucionais comuns, efetivados através de mútua colaboração por meio de diversas formas, tais como repasse de verbas, uso de equipamentos, uso de recursos humanos e materiais, uso de imóveis, dentre outras (BEZERRA, 2008, p.62).

Segundo Silveira (2009), o convênio é um instrumento utilizado pela Administração Pública para associarse a entidades públicas ou privadas, que "Tem características próprias e "no que couber" segue as normas relativas ao processo de licitação, regidas pela Lei n 8.666/93" (p. 155). No contrato os interesses são opostos e contraditórios, e no convênio os interesses institucionais e resultados são comuns e verifica-se a mútua colaboração. Para Domiciano (2009),

Como o convênio pressupõe mútua colaboração não se faz necessária a licitação, pode celebrar-se entre pessoas jurídicas da mesma esfera governamental: União, Estados, Distrito Federal e Municípios, entre órgãos e entidades da Administração Pública de esferas governamentais distintas ou entre a Administração Pública e entidades privadas (p.91).

Os convênios podem ser anulados a qualquer momento. No que se refere à prestação de contas dos recursos recebidos, segue determinação da CF/88 (SILVEIRA, 2009). Conforme segue:

Prestará contas qualquer pessoa física ou jurídica, pública ou privada, que utilize, arrecade, guarde, gerencie ou administre dinheiros, bens e valores públicos ou pelos quais a União responda, ou que, em nome desta, assuma obrigações de natureza pecuniária (BRASIL, 1988, Art. 70, parágrafo único).

Segundo Di Pietro (2006) o vocábulo parceria, em sentido amplo, designa todos os ajustes entre o poder público e o particular para consecução de fins de interesse público, já a expressão parceria público-privada (PPP) designa apenas dois tipos de parceria: a concessão patrocinada e a concessão administrativa. Fizemos esta ressalva, pois em 30 de dezembro de 2004 foi promulgada a Lei n 11.079, que instituiu normas gerais para licitação e contratação de parceria público-privada no âmbito da Administração Pública e reservou a expressão parceria público-privada para duas modalidades especificas de parceria, conforme apontamos. Até então quando a Constituição Federal se referia à concessão, tinha que se entender que a referência era à concessão de serviço público.

Segundo Bezerra (2008), "A 'parceria' pode servir a variados objetivos e formalizar-se por diferentes instrumentos jurídicos. Pode ser utilizada como forma de delegação, fomento, cooperação ou desburocratização." (p.43). Sendo que a delegação consiste na transferência da execução de serviços públicos a particulares, pelo instrumento da concessão que pode se apresentar dentro de algumas modalidades: a) Concessão e permissão de serviço público ordinária, comum ou tradicional; b) Concessão de obra pública; c) Concessão patrocinada, concessão administrativa; d) Concessão de uso de bem público (BEZERRA, 2008).

Segundo Di Pietro (2006), em muitos contratos existe a conjugação de várias modalidades, em que uma constitui o objeto principal e a outra, o acessório. Para a autora todas as formas de concessão constituem instrumentos de que o poder público pode utilizar-se para diminuir o tamanho do Estado.

Como já salientamos a Lei no 11.079, de 30.12.2004, cria novas modalidades de contratos administrativos - a concessão patrocinada e a concessão administrativa - sob o título de parcerias público-privadas - PPP. Na concessão patrocinada, a contribuição pecuniária do poder público pode chegar a 70\% da remuneração total garantida ao 
parceiro privado (podendo superar esse montante se houver autorização legislativa) soma-se à tarifa cobrada do usuário. Já na concessão administrativa, toda a remuneração fica a cargo do poder público (DI PIETRO, 2005).

A modalidade de parceria concessão administrativa tem por objeto "a prestação de serviços de que a Administração Pública seja a usuária direta ou indireta, ainda que envolva a execução de obra ou fornecimento e instalação de bens" (BRASIL, 2004). Segundo Di Pietro (2005) "[...] a concessão administrativa constitui-se em um misto de empreitada (porque a remuneração é paga pelo parceiro público) e de concessão de serviço público (porque o serviço prestado pode ter a natureza de serviço público e está sujeito a algumas normas da Lei 8.987)" (p.s/n).

Ainda segundo a autora,

Se 0 objeto do contrato for a prestação de serviço público, haverá terceirização de atividade-meio (obras e serviços administrativos) e atividade-fim (serviços públicos, especialmente serviços sociais do Estado, que não admitem instituição de tarifa). Sob certo aspecto, haverá o mesmo tipo de terceirização de atividade fim que ocorre com as organizações sociais, porém com regime jurídico diverso. Nos dois casos, a ideia é a de delegar a entidade privada a execução de serviço público; só que, no caso das organizações sociais, a entidade tem que ser associação ou fundação sem fins lucrativos e, no caso da concessão administrativa, essa exigência não existe, podendo a concessionária atuar com objetivo de lucro. Nos dois casos, haverá a delegação de serviço público não exclusivo do Estado, prestado por entidade privada, mediante remuneração garantida pelo poder público (DI PIETR0, 2005, p. s/n. grifos nossos).

$\mathrm{Na}$ pesquisa "Oferta Educacional nas creches e parcerias público-privado nos municípios paulistas de 100.000 a 500.0002" analisou-se 30 municípios paulistas que apresentavam parceria para oferta de vagas na educação infantil.

Nos municípios de Americana, Araçatuba, Araras, Atibaia, Cubatão, Diadema, Embu, Ferraz de Vasconcelos, Franca, Guarujá, Hortolândia, Itapecerica da Serra, Itaquaquecetuba, Itu, Jacareí, Jundiaí, Mauá, Mogi, Piracicaba, Presidente Prudente, Santa Bárbara d' Oeste, São Caetano do Sul, São Carlos, São Vicente, Sumaré, Suzano e Taboão da Serra os dados indicam que as parcerias adotadas dizem respeito ao instrumento jurídico convênio. Nos municípios de Franco da Rocha e Francisco Morato as parcerias já foram encerradas, mas pelos dados observou-se que as mesmas se deram também por meio de convênio.

Esta relação, em si, não constitui novidade uma vez que tradicionalmente no caso das creches, o poder público delegou à iniciativa privada a tarefa de atender a demanda. Como salienta Borghi (2009), o atendimento em creches tem o seu início a partir não só de iniciativas do poder público, mas também das próprias comunidades, principalmente em instituições comunitárias, filantrópicas e assistenciais. Essas instituições privadas receberam subsídios públicos, razão pela qual o Estado, ou a ausência deste na oferta dessa política, aparece, desde sempre, como indutor da proliferação de convênios entre a esfera pública e a privada.

No Brasil, portanto, é possível falar de uma tradição de convênios entre prefeituras e instituições privadas de educação infantil, pois grande parte das prefeituras em todo o país há muito mantém relações com instituições confessionais, filantrópicas e comunitárias que atendem crianças na faixa etária de 0 a 6 anos.

Dessa forma, esses casos não se configuram como uma parceria público-privada no sentido jurídico estrito tal como as modalidades de Concessão Patrocinada e Concessão Administrativa, regulamentadas pela Lei 11.079, de 30 de dezembro de 2004, que instituiu normas gerais para licitação e contratação de parceria público-privada no âmbito da administração pública (BEZERRA, 2008).

Já no município de Limeira, diferentemente dos demais, o instrumento legal que regula a parceria é o Termo de Concessão. No caso desse município, a parceria constitui-se de concessão administrativa, pois é delegada à entidade privada a execução de serviço público, a entidade concessionária pode atuar com objetivo de lucro, e isso ocorre, pois as instituições conveniadas são privadas com fins lucrativos. Portanto, a parceria nesse município configura como uma parceria público-privada no sentido jurídico estrito. Assim, no município de Limeira a parceria do poder público municipal com instituições privadas para oferta de vagas na educação

2 Pesquisa de Iniciação Científica financiada pela FAPESP - processo nº 2009/16012-2 
infantil, enquadra-se na modalidade "concessão patrocinada, concessão administrativa".

Logo, observa-se que Limeira optou pela concessão, pois essa permite ao concessionário receber recursos públicos e atuar com objetivo de lucro, o que não é possível no convênio. Importante ressaltar que outros municípios (Piracicaba, Hortolândia e Sumaré) também apresentam parceria com instituições privadas com fins lucrativos, e mesmo assim adotaram o convênio, ainda que no município de Piracicaba, por exemplo, as matrículas privadas conveniadas sejam contabilizadas como públicas para recebimento dos recursos do Fundo de Manutenção e Desenvolvimento da Educação Básica e de Valorização dos Profissionais da Educação (Fundeb) (DOMICIANO, 2009).

Segundo Domiciano (2009), as escolas privadas que visam o lucro não estão habilitadas a receberem recursos públicos, pois não são comunitárias, confessionais ou filantrópicas, conforme especifica o art. 20 da LDB, assim "[...] o advento da subvenção pública, aos estabelecimentos privados stricto sensu, introduzido pelo Programa 'Bolsa Creche' não encontra respaldo legal nas legislações brasileiras". Nota-se que as instituições privadas com fins lucrativos têm aproveitado as "brechas" de outras legislações (como é o caso da Lei $n^{\circ}$ 11.079) para receberem subsídios públicos.

Nesse sentido, concordamos com Di Pietro (2005), que "[...] a instituição da PPP se insere na tendência à privatização, entendida em sentido amplo, de modo a abranger todos os institutos de que o Estado vem lançando mão para diminuir o seu aparelhamento administrativo, o seu quadro de pessoal, o regime jurídico administrativo a que se sujeita" (p. s/n). Para Di Pietro, outra grande preocupação em relação à lei ( $n^{\circ}$ 11.079) "[...] decorre do fato de o Governo (que afirma não ter recursos para execução direta das atividades a serem objeto de PPP), contraditoriamente assumir, na posição de parceiro público, o compromisso de pagar contribuição ao parceiro privado, além de empenhar o orçamento público para garantir o parceiro privado com garantias que apresentam fortes traços de inconstitucionalidade" (p. s/n). O que torna até mesmo questionável a justificativa apresentada ao projeto de lei, onde os objetivos da PPP seriam os de suprir a falta de disponibilidade de recursos financeiros.

\section{Considerações finais}

Em função da reforma do Estado, ocorrida durante a década de 1990, a implementação de parcerias entre a esfera pública, entendida como estatal, e a privada veio a se consolidar e assumir novos contornos. Na área educacional a articulação entre a esfera pública e a privada apresenta uma tendência crescente (ADRIÃO; BORGHI, 2008).

Observa-se que a parceria serve a diversas finalidades e formaliza-se por diferentes instrumentos jurídicos. No caso das parcerias para oferta de vagas na educação infantil o instrumento mais utilizado é o convênio, entretanto, já se nota que outros instrumentos começam a ser utilizados, uma vez que por meio de convênio não é possível repassar recursos públicos a instituições com fins lucrativos. Ao se transferir recursos públicos a instituições privadas é primordial que haja o controle desses recursos transferidos, com a devida transparência do processo e a prestação de contas (SILVEIRA, 2009).

Outra ressalva em relação à adoção de parcerias é a tendência de privatização do ensino público impulsionada pelas mesmas. Pois conforme apontam Adrião e Borghi (2008), há de se considerar que as parcerias pouco, ou nada, colaboram para a diminuição das desigualdades existentes no campo educacional. Segundo Rossi (2008),

[...] há de se pensar que conseqüências estas reformas, entre elas a tendência de consolidação de parcerias entre poder público e esfera

privada, têm trazido aos usuários dessas políticas. Será que estas têm contribuído para a diminuição das desigualdades ou tem servido apenas para dotar 0 aparelho estatal de maior racionalidade técnica? (p.49).

Nos municípios analisados observa-se a tendência de uma política de ampliação da oferta de educação infantil a partir da rede privada e com incentivo público através do atendimento por meio de parcerias/convênios, entretanto, é importante levar em consideração as questões apontadas por Adrião e Borghi (2008) e Rossi (2008) no que diz respeito à expansão de parcerias, principalmente na área educacional. 


\section{Referências bibliográficas}

ADRIÃO, T.; BORGHI, R. Parcerias entre prefeituras e esfera privada: Estratégias privatizantes para a educação pública em São Paulo? In: ADRIÃO, T.; PERONI, V. (Org.). Público e Privado na Educação: novos elementos para o debate. São Paulo: Xamã Editora, 2008. p. 99-110.

ADRIÃO, T; GARCIA, T.; BORGHI, R.; ARELARO, L. Estratégias municipais para a oferta da Educação Básica: Análise das parcerias público-privado no estado de São Paulo. Relatório de pesquisa. Fapesp, 2009.

BEZERRA, E. Parceria público-privada nos municípios de Brotas e Pirassununga: estratégias para a oferta do ensino? 2008. Dissertação (Mestrado em Educação) - Universidade Estadual Paulista, Rio Claro, 2008.

BORGHI, R. Oferta Educacional nas creches: Arranjos Institucionais entre o Público e o Privado. Projeto de Pesquisa (CNPq), 2009.

BRASIL. Congresso Nacional. Constituição da República Federativa do Brasil. Brasília: Senado Federal, Centro Gráfico, 1988.

BRASIL. Lei ñ. 9.424, de 24 de dezembro de 1996. Institui o Fundo de Manutenção e Desenvolvimento do Ensino Fundamental e de Valorização do Magistério. Brasília, 1996. Diário Oficial da União. Brasília, 25 de dezembro de 1996.

BRASIL, Lei $\mathbf{n}^{\mathbf{1}} \mathbf{1 1 . 0 7 9}$, de 30 de dezembro de 2004. Institui normas gerais para licitação e contratação de parceria público-privada no âmbito da administração pública. Disponível em: < http://www.planalto.gov.br/ ccivil_03/_ato2004-2006/2004/lei/l11079.htm> Acesso em: 17 de setembro de 2010.

DI PIETRO, M. S. Reflexões sobre as parcerias público-privadas. Jornal Carta Forense. Set. 2005 Disponível em<http://www.azevedosette.com.br/ppp/artigos/reflexoes.html> Acesso em 05 de outubro de 2009.

DI PIETRO, M. S. Parcerias na Administração Pública: concessão, permissão, franquia, terceirização, parceria público-privada e outras formas. 5 ed. São Paulo: Atlas, 2006.

DOMICIANO, C. A. O Programa 'Bolsa Creche' nos municípios paulistas de Piracicaba e Hortolândia: uma proposta para alocação de recursos estatais à educação privada? 226f. Dissertação (Mestrado em Educação) - Instituto de Biociências, Universidade Estadual Paulista, Rio Claro, 2009.

OLIVEIRA, J. Oferta educacional nas creches e parcerias público-privado nos municípios paulistas de $\mathbf{1 0 0 . 0 0 0}$ a $\mathbf{5 0 0 . 0 0 0}$ habitantes. Trabalho de Conclusão de Curso (Licenciatura Plena em Pedagogia) - Instituto de Biociências, Universidade Estadual Paulista, Rio Claro, 2010.

PIRES, D. O. A configuração jurídica e normativa da relação público-privada no Brasil na promoção do direito à educação. Dissertação (Mestrado em Educação) - Universidade Federal do Rio Grande dos Sul, Porto Alegre, 2009.

ROSSI, L. Parcerias entre o Poder Público e a Esfera Privada como instrumentos de descentralização da ação estatal: diferentes perspectivas. Educação: Teoria e Prática - v. 18, n.31, p.35-52 jul./dez. 2008.

SILVEIRA, A. D. Algumas considerações sobre as normas do processo de licitação pública, contratos e convênios no estabelecimento de parcerias educacionais entre a administração pública e a esfera privada. Educação: Teoria e Prática - v. 19, n.32, p.143-159. jan./jun. 2009.

Recebido em Fevereiro de 2012 Aprovado em Abril de 2013 